\title{
Implementasi Bahasa Pemrograman Java Untuk Pengontrolan Aset Kantor Pada Dinas Kebudayaan Dan Pariwisata Provinsi Sumatera Barat
}

\author{
Debi Setiawan \\ DosenTeknologi Informatika STMIK-AMIK RIAU \\ debisetiawan9090@gmail.com
}

\begin{abstract}
ABSTRAK
Pemanfaatan teknologi komputer dalam proses pengontrolan data aset pada Kantor Dinas kebudayaan dan Pariwisata Provinsi Sumatera Barat belum efektif dan efisien sehingga dalam pembuatan laporan pengontrolan aset waktu yang lama. Dengan menggunakan desain sistem yang baru untuk membantu dalam pengontrolan data aset, menghasilkan suatu system yang diinginkan maka dibuatlah suatu sistem yaitu dengan menggunakan bahasa Pemrograman Java berbasis Database MySQL. Dalam hal ini penulis menggunakan beberapa metode dalam mengumpulkan data diantaranya adalah penelitian lapangan, dan penelitian perpustakan. Dimana data-data yang diperoleh dikelompokan terlebih dahulu dan dalam analisa dan hasil digunakan Aliran system Informasi (ASI), Contex Diagram, Data Flow Diagram (DFD), Entity Relationship Diagram(ERD), dan Flowchart yag didukung dengan alat Bantu komputer sehingga menghasilkan database. Diterapkan sistem yang baru ini nantinya akan meningkatkan kualitas informasi yang dihasilkan sehingga rancangan-rancangan tersebut dapat bermanfaat bagi perusahaan yang bersangkutan.
\end{abstract}

Kata kunci: Implementasi, Java, Msysql, Pengontrolan Aset Kantor

\section{PENDAHULUAN}

Pada masa sekarang ini perkembangan ilmu pengetahuan dan teknologi terus maju dengan pesatnya. Hal ini telah mendorong berbagai perubahan-perubahan yang sangat cepat di berbagai segi kehidupan, dan tidak dipungkiri lagi perubahan-perubahan tersebut memang sangat terasa sekali dalam kehidupan sehari-hari. Salah satu hasil pemanfaatan kemajuan teknologi adalah penggunaan komputer, yang ada pada masa sekarang maupun masa yang akan datang memang sangat dibutuhkan, karena telah terbukti bahwa komputer merupakan alat bantu dalam menyelesaikan pekerjaan manusia secara cepat, akurat dan efesien.

Dalam pemanfaatan komputer kali ini penulis menggunakan bahasa pemrograman berbasis visual dan database yang bebas dari isu license dan memang bersifat open source untuk menghasilkan sebuah program yang powerfull dan portable.

Namun permasalahanya terletak pada pengontrolan data Dinas Kebudayaan dan 
Pariwisata Sumatera Barat, karena belum adanya sebuah sistem yang tepat untuk mempermudah kinerja dalam mengontrol data aset, masih menggunakan cara manual, melihat didalam lemari untuk melihat laporan aset apa saja yang kurang maupun rusak di masing masing tempat.

Dengan dibuatnya sistem ini, dapat memberikan informasi-informasi yang di butuhkan dalam pengambilan keputusan untuk perkembangan dan pihak pariwisata dapat mengoptimalkan kerja pada Dinas Pariwisata.

\section{METODE PENELITIAN}

Dalam melakukan penelitian ini, metode yang digunakan dalam mengumpulkan data adalah :

1. Penelitian Lapangan (Field research)

Teknik yang digunakan diantarannya :
a. Observasi
b. Wawancara

2. Penelitian Perpustakaan (Library research)

3. Penelitian laboratorium ( Laboratory research)

Penelitian yang dilakukan dengan menggunakan hardware dan software.
a. Hardware
b. Software

Software merupakan sekumpulan data elektronik yang disimpan dan diatur oleh komputer

\section{ANALISA SISTEM}

\section{A. AliranSistemInformasi(ASI)Lama}

Aliran sistem informasi yang sedang berjalan pada Dinas Kebudayaan Dan Pariwisata Provinsi Sumatera Barat dapat dilihat pada gambar 3.1 berikut:

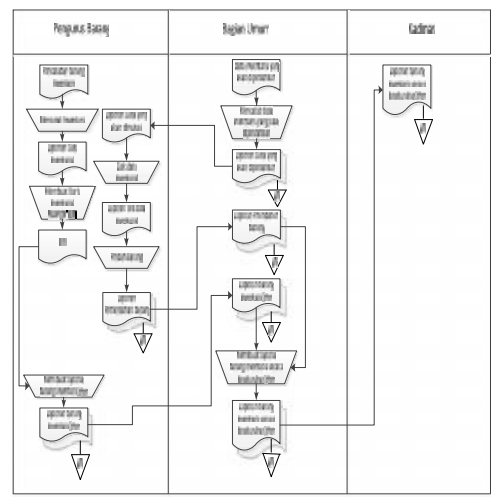

Gambar 3.1

\section{AliranSistemInformasi(ASI) Lama}

Pengontrolan aset kantor Dinas Kebudayaan dan Pariwisata Provinsi Sumatera Barat.

\section{B. Evaluasi Sistem yang Ada}

Dilihat dari bentuk sistem yang sedang berjalan pada Dinas Pariwisata dapat diambil beberapa point pokok yaitu berupa kekurangan yang harus diperbaiki pada sistem yang ada sekarang, antara lain:

1. Pada Instansi ini banyak data yang diolah secara manual, sehingga mengakibatkan kekeliruan dan keterlambatan dalam pembuatan laporan dan pengontrolan aset yang dibutuhkan. 
2. Dokumentasi data dilakukan secara berulang-ulang karena disimpan ke dalam bentuk arsip.

3. Pencarian tentang data yang dibutuhkan memakan waktu yang cukup lama karena data yang ada disimpan ke dalam lemari arsip yang jumlah datanya sudah sangat banyak.

\section{DesainSistem}

Tahap ini dilakukan setelah tahap penganalisaan sistem yang mendefinisikan kebutuhan fungsional sistem dan sebagai persiapan rancang bangun implementasi agar sistem baru yang diusulkan dapat diimplementasikan dengan memuaskan. Desain sistem ini terbagi atas dua yaitu desain global dan desain terinci.

\section{Desain Global}

Desain sistem secara global adalah suatu perancangan yang menerangkan elemen-elemen secara garis besar, dan apa saja yang akan mendukung untuk terwujudnya suatu sistem baru.

Aliran Sistem Informasi

(ASI) Pengontrolan aset yang baru padaPengontrolan Aset Kantor Dinas Kebudayaan dan Pariwisata Sumatera Barat dapat dilihat pada gambar 3.2 sebagai berikut:

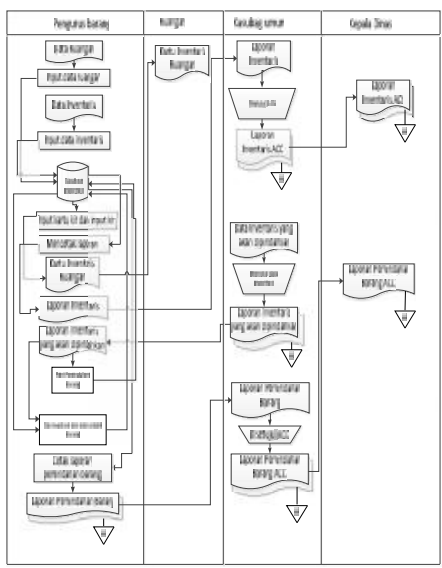

Gambar 3.2 AliranSistemInformasi(ASI) Baru

Pengontrolan aset kantor Dinas Kebudayaan

dan Pariwisata Provinsi Sumatera Barat.

\subsection{Context Diagram}

Context Diagram adalah gambaran umum tentang suatu sistem yang terdapat di dalam suatu organisasi yang memperlihatkan batasan (boundary) sistem, adanya interaksi antara eksternal entity dengan suatu sistem, dan informasi secara umum mengalir di antara entity dan sistem. Adapun Context Diagram dari sistem informasi yang berjalandapat dilihat pada Gambar 3.3 dibawah ini:

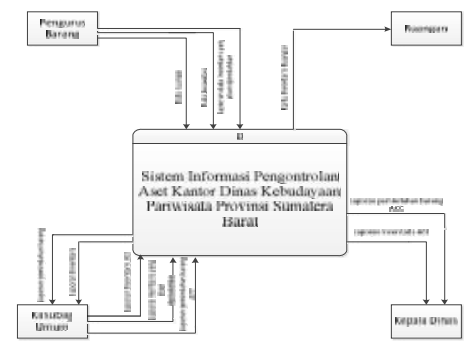

Gambar 3.3 Context Diagram 


\subsection{Data Flow Diagram (DFD)}

DFD dapat dilihat pada Gambar 3.4

Data Flow Diagram (DFD) level 0.

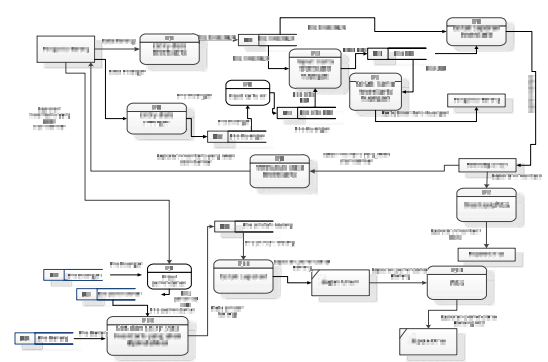

Gambar 3.4 Data Flow Diagram (DFD) Level 0

\subsection{Entity Relationship Diagram (ERD)}

Entity Relationship Diagram (ERD) dapat dilihat pada Gambar 3.5 dibawah ini :

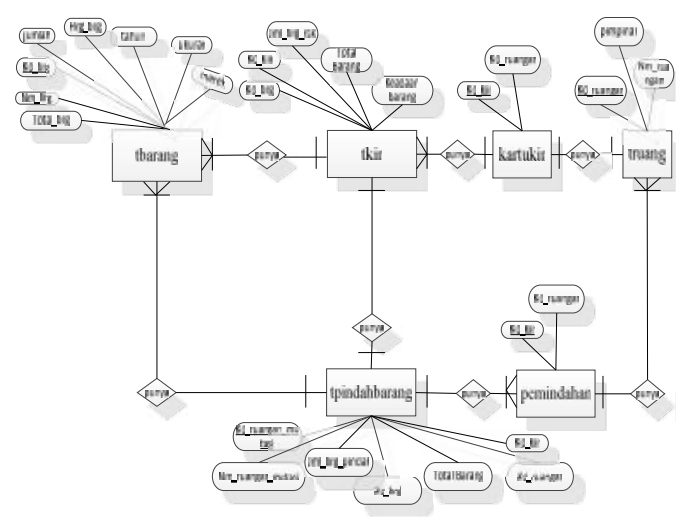

Gambar 3.5 Entity Relationship Diagram (ERD)

\subsection{Struktur Program}

Gambar 3.6 merupakan struktur program aplikasi yang dirancang secara keseluruhan.

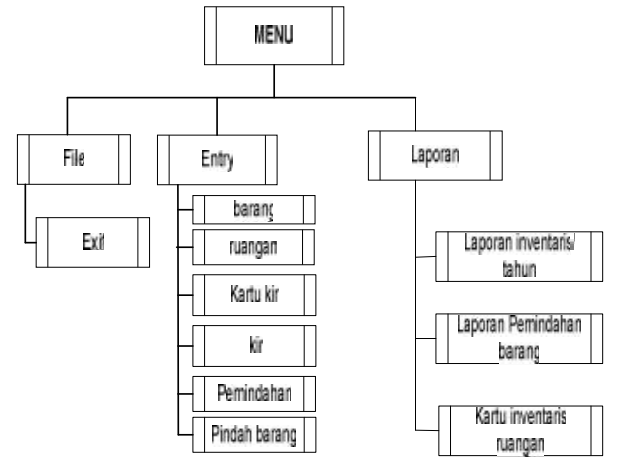

Gambar 3.6 Struktur Program

\section{DesainTerinci}

Design terinci terdiri dari:

\subsection{Desain Output}

Adapun disain output yang dirancang dapat dilihat pada Gambar berikut :

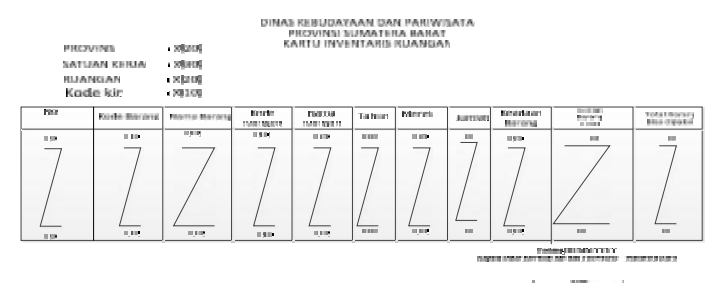

Gambar 3.7 Kartu Inventaris Ruangan(KIR)

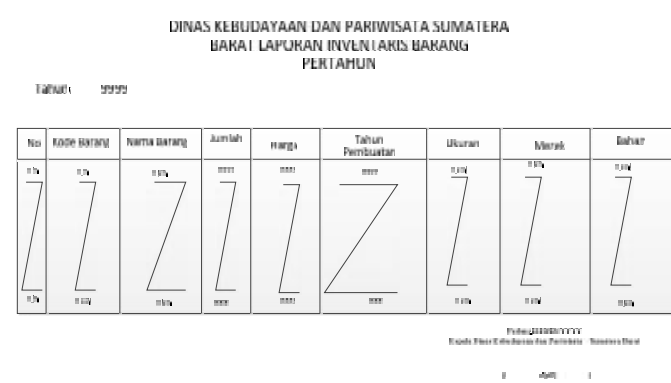

Gambar 3.8 Laporan Inventaris

Barang/Tahun 


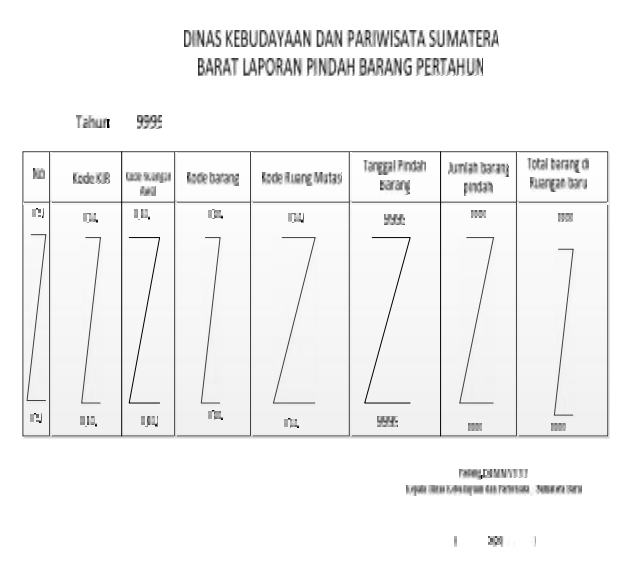

Gambar 3.9 Informasi Data Perpindahan

Barang Pertahun

\subsection{Desain Input}

Adapun desain yang drancang terlihat pada Gambar berikut:

\section{1) Entry Data Ruangan}

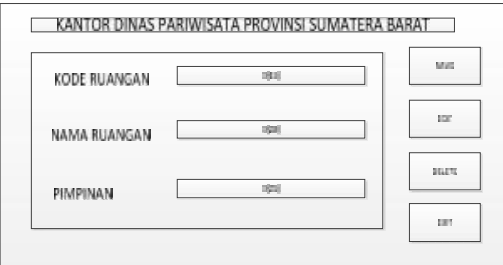

Gambar3.10 Input Data Ruangan

\section{2) Entry Data Barang}

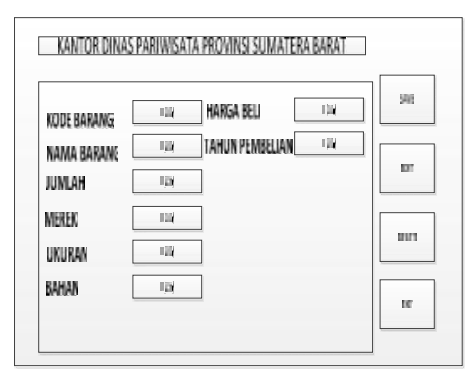

Gambar3.11 Input Data Barang

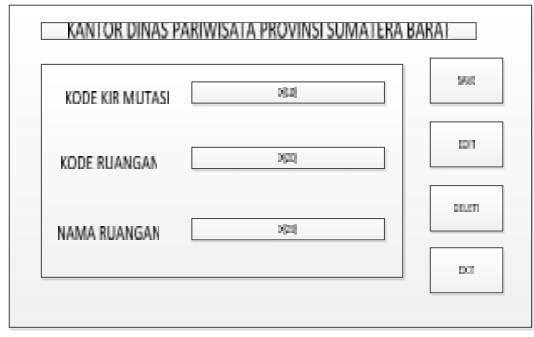

Gambar3.12 Input Data Pemindahan

\section{4) Entry Data Pindah Barang}

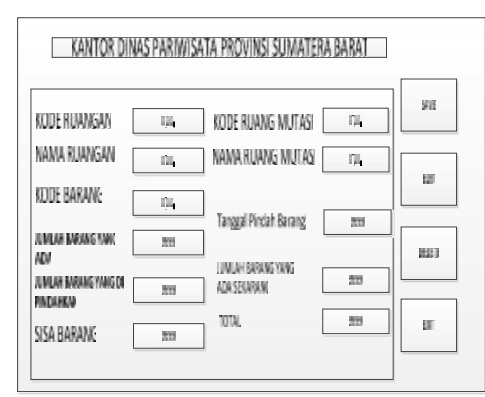

Gambar3.13 Input Data Pindah

Barang

\section{5) Entry Data Kartu kir}

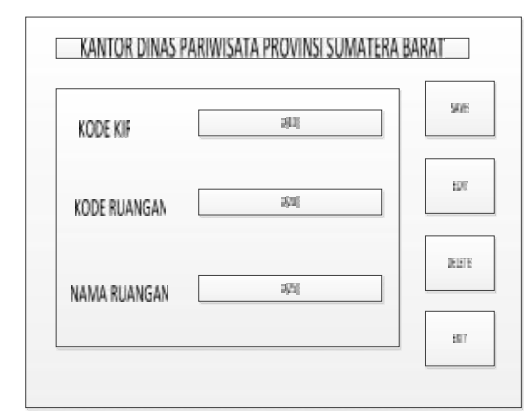

Gambar3.14 Input Data Kartu kir

\section{3) Entry Data Pemindahan}


6) Entry Kartu Inventaris Ruangan

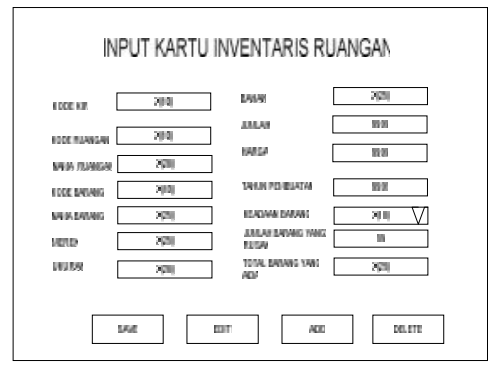

Gambar3.15 Input Data Kartu Inventaris Ruangan

\subsection{Disain File}

Desint File terdiri dari :

\section{1) File Barang}

Tabel 3.1 Rancangan File Barang

Database : db_inventaris.sql

Table Name : tbarang

Field Key Kd_brg

\begin{tabular}{|c|l|l|l|l|l|}
\hline $\begin{array}{c}\text { N } \\
\text { o }\end{array}$ & $\begin{array}{l}\text { Field } \\
\text { Name }\end{array}$ & Type & $\begin{array}{l}\text { Wid } \\
\text { th }\end{array}$ & $\begin{array}{l}\text { Deci } \\
\text { mal }\end{array}$ & $\begin{array}{l}\text { Descripti } \\
\text { on }\end{array}$ \\
\hline 1 & Kd_b & Varc & 10 & - & KodeBar \\
2 & rg & har & 25 & - & ang \\
3 & Nm_ & Varc & 20 & - & NamaBar \\
4 & brg & har & 20 & - & ang \\
5 & Jumla & Integ & 20 & - & Jumlah \\
6 & h & er & 10 & - & HargaBar \\
7 & Hrg_ & Integ & 20 & - & ang \\
8 & brg & er & 25 & - & Bahan \\
& Baha & Varc & & & Tahun \\
\hline
\end{tabular}

\section{2) File Ruangan}

Tabel 3.2 Rancangan File Ruangan

Database : db_inventaris.sql

Table Name : truangan

Field Key $\quad$ : Kd_ruangan

\begin{tabular}{|c|l|l|l|l|l|}
\hline N & $\begin{array}{l}\text { Field } \\
\text { N }\end{array}$ & Type & $\begin{array}{l}\text { Wi } \\
\text { dth }\end{array}$ & $\begin{array}{l}\text { Deci } \\
\text { mal }\end{array}$ & $\begin{array}{l}\text { Descripti } \\
\text { on }\end{array}$ \\
\hline 1 & Kd_ruan & Varc & 10 & - & KodeRua \\
2 & gan & har & 20 & - & ngan \\
3 & Nm_rua & Varc & 25 & - & NamaRua \\
\hline
\end{tabular}

\section{3) File Pemindahan}

\section{Tabel 3.3 Rancangan File Pemindahan}

Database $\quad$ : db_inventaris.sql

Table Name : truangan

Field Key $\quad$ : Kd_kir,Kd_ruangan

\begin{tabular}{|c|l|l|l|l|l|}
\hline $\begin{array}{c}\text { N } \\
\text { o }\end{array}$ & $\begin{array}{l}\text { Field } \\
\text { Name }\end{array}$ & Type & $\begin{array}{l}\text { Wid } \\
\text { th }\end{array}$ & $\begin{array}{l}\text { Deci } \\
\text { mal }\end{array}$ & $\begin{array}{l}\text { Descript } \\
\text { ion }\end{array}$ \\
\hline 1 & Kd_kir & Varc & 10 & - & Kode \\
2 & Kd_ruan & har & 20 & - & Kir \\
3 & gan & Varc & 25 & - & Kode \\
\hline
\end{tabular}

\section{4) File Pemindahan Barang}

Tabel 3.4 Rancangan File Pindah Barang

Database $\quad$ : db_inventaris.sql

Table Name : tpindahbarang

Field Key ： Kd_brg_mutasi 


\begin{tabular}{|c|l|l|l|l|l|}
\hline N & Field & Typ & Wi & Dec & Descriptio \\
o & Name & e & dth & imal & $\mathrm{n}$ \\
\hline 1 & Kd_ruang_ & Var & 10 & - & Kode \\
2 & mutasi & cha & 20 & - & ruang \\
3 & Nm_ruang & $\mathrm{r}$ & 10 & - & mutasi \\
4 & an_mutasi & Var & 10 & - & Nama \\
5 & Kd_barang & cha & 10 & - & ruang \\
6 & Kd_ruanga & r & 20 & - & mutasi \\
7 & n & Var & 30 & - & KodeBara \\
& Kd kir & cha & & & ng \\
\hline
\end{tabular}

\section{5) File Kartu Kir}

\section{Tabel 3.5 Rancangan File Kartu Kir}

Database $\quad$ : db_inventaris.sql

Table Name : tkartukir

Field Key $\quad$ : Kd_kir,Kd_ruangan

\begin{tabular}{|c|c|c|c|c|c|}
\hline o & $\begin{array}{l}\text { Field } \\
\text { Name }\end{array}$ & Type & $\begin{array}{l}\text { Wid } \\
\text { th }\end{array}$ & $\begin{array}{l}\text { Deci } \\
\text { mal }\end{array}$ & $\begin{array}{l}\text { Descript } \\
\text { ion }\end{array}$ \\
\hline 1 & Kd_kir & Varc & 10 & - & Kode \\
\hline 2 & Kd_ruan & har & 20 & - & Kir \\
\hline 3 & gan & Varc & 25 & - & Kode \\
\hline & Nm_ruan & har & & & Ruanga \\
\hline & & Varc & & & \\
\hline
\end{tabular}

\section{6) File Kartu Inventaris Ruangan}

Tabel 3.6 Rancangan File Kartu Inventaris

\section{Ruangan}

Database : db_inventaris.sql

Table Name : tkir

Foreign Key : Kd_kir

\begin{tabular}{|c|l|c|c|c|l|}
\hline $\begin{array}{c}\text { N } \\
\text { o }\end{array}$ & $\begin{array}{l}\text { Field } \\
\text { Name }\end{array}$ & $\begin{array}{l}\text { Typ } \\
\text { e }\end{array}$ & $\begin{array}{l}\text { Wi } \\
\text { dth }\end{array}$ & $\begin{array}{l}\text { Deci } \\
\text { mal }\end{array}$ & $\begin{array}{l}\text { Descriptio } \\
\mathrm{n}\end{array}$ \\
\hline 1 & Kd_kir & Var & 10 & - & Kodekir \\
2 & Kd_baran & char & 10 & - & kodebaran \\
3 & g & Var & 20 & - & g \\
4 & Jumlah_br & char & 20 & - & jumlahbar \\
5 & g_rusak & inte & 20 & - & angrusak \\
\hline
\end{tabular}

\section{IMPLEMENTASI DAN PENGUJIAN}

\subsection{Menu Utama}

Form menu utama dapat dilihat pada

Gambar 3.1

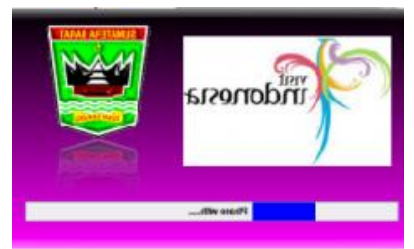

Gambar 3.1 loading system

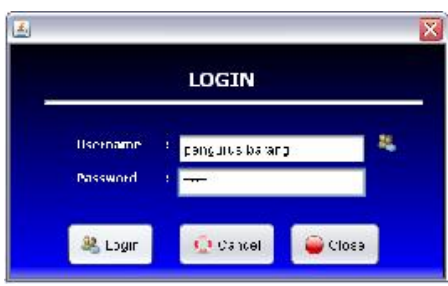

Gambar 3.2 login 


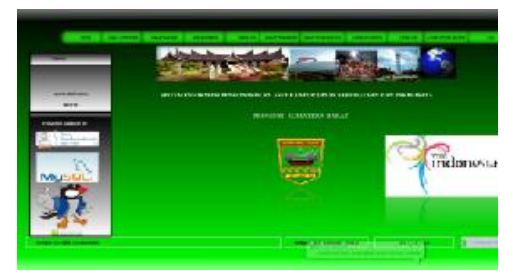

Gambar 3.3 Form Menu Utama

\subsection{Sub Menu Entry}

Dari menu utama menu paling kiri adalah menu entry dari semua data yang akan dipakai untuk operasi berikutnya.

1. Data inventaris

Form entry data inventaris dapat dilihat pada Gambar 3.4.

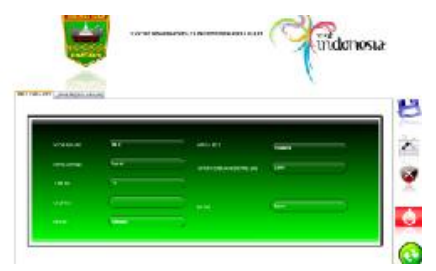

\section{Gambar 3.4 Form Menu Entry Data}

Inventaris

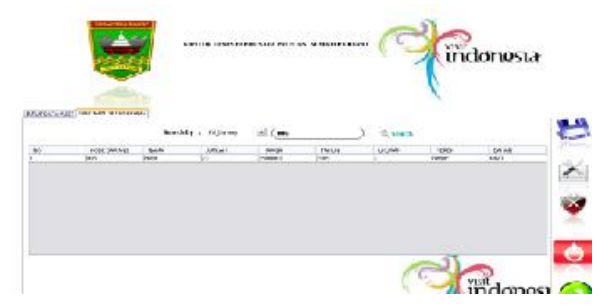

Gambar 3.5 Form Cari Barang
2. Ruangan

Form entry data ruangan dapat dilihat pada Gambar 3.6.

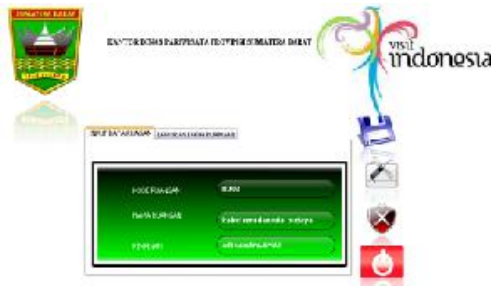

Gambar 3.6 Form Menu Entry Data Ruangan

3. Entry Kartu Kir

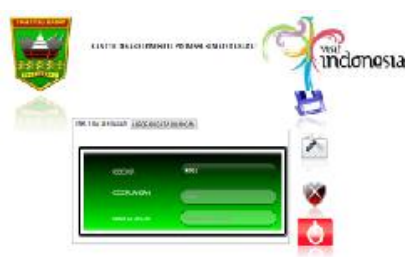

Gambar 3.7 Form Menu Entry Kartu Kir

4. Entry data kir

Untuk menu entDapat dilihatpada Gambar 3.8.

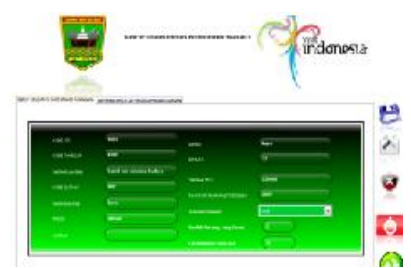

Gambar 3.8 Form Menu Entry Data Kir 


\section{Jurnal Edik Informatika}

ISSN : 2407-0491

E-ISSN : 2541-3716

Penelitian Bidang Komputer Sains dan Pendidikan Informatika

5. Entry Pemindahan

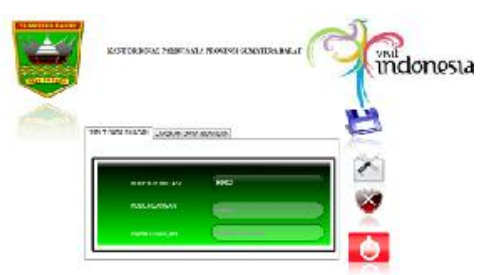

Gambar 3.9 Form Menu Entry Data

Pemindahan

6. Pindah barang

Form entry data pindah barang dapat dilihat pada Gambar 3.10.

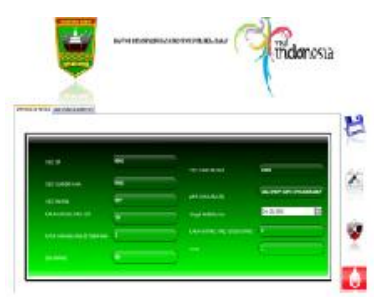

Gambar 3.10 Form Menu Entry Data Pindah barang

\subsection{Sub Menu Laporan}

Pada sub menu laporan dapat ditampilkan laporan data produksi perkode kayu,bulanan dan tahunan sebelum kita mencetaknya ke printer. Laporan-laporan yang dihasilkan antara lain:

1. Laporan KIR pertahun

Form laporan produksi perkode kayu dapat dilihat pada Gambar 3.11.

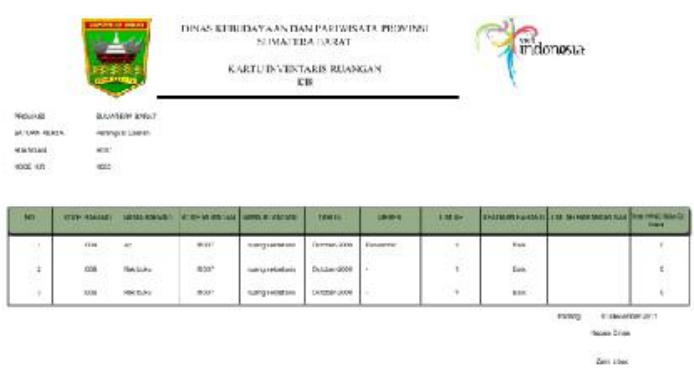

Gambar 3.11Laporan Kartu Inventaris Pertahun

2. Laporan inventaris pertahun

Form laporan inventaris pertahun ini dapat dilihat pada Gambar 3.12.

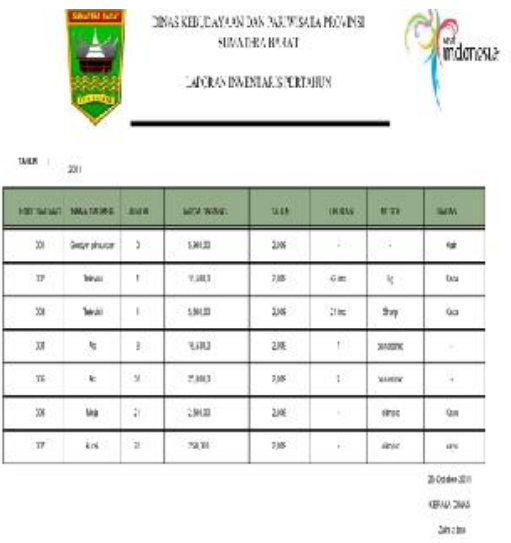

Gambar 3.12 Form Menu Laporan data inventaris pertahun

3. Laporan pindah barang pertahun

Form laporan pindah barang pertahun dapat dilihat pada Gambar 3.13. 

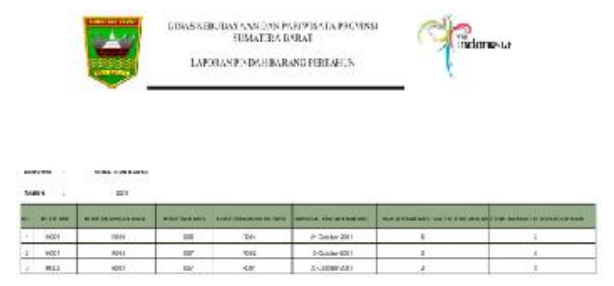

Gambar 3.13 Form Laporan Pindah Barang

\section{KESIMPULAN}

Pengontrolan aset kantor merupakan suatu unit kerja yang terdapat didalam sistem yang dimiliki oleh Kantor Dinas Kebudayaan dan Pariwisata Provinsi Sumatera Barat. Pengontrolan aset erat kaitanya dengan perpindahan aset maupun mendata aset yang rusak,

Dari uraian dan penjelasan yang telah diterapkan pada bab-bab sebelumnya serta didukung hasil analisa terhadap sistem pengontrolan aset kantor pada Dinas Kebudayaan dan pariwisata Provinsi Sumatera Barat, ditemukan bahwa :

1. Dengan penggunaan sistem komputerisasi secara optimal memberikan manfaat yang besar pada kantor Dinas Kebudayaan dan Pariwisata Provinsi Sumatera Barat yang dapat meningkatkan kinerja dan menghasilkan informasi yang akurat,cepat dan dapat memberikankemudahan kepada pengurus barang selaku pelaksana dalam penggunaan sistem informasi pengontrolan aset.

2. Dengan memakai computer dan Bahasa pemrograman visual dan database opensource yang mendukung dalam pengontrolan data dan pnyajian laporan dapat dilakukan dengan akurat cepat,dan efesien sesuai dengan prosedur yang diterapkan.

3. Kinerja pengontrolan aset lebih teratur,terutama dalam Pengontrolan data aset dalam bentuk database dapat mengurangi tempat, penyimpanan membantu proses pencarian data dan dapat digunakan setiap saat.

\section{DAFTAR PUSTAKA}

Amundsen, Michael \& Curtis Smith. 2001. Microsoft Visual Basic. Edisi Bahasa Indonesia, Andi. Yogyakarta

Jogiyanto, H.M.2001. Analisa \& Disain Sistem Informasi. Andi Offiset. Yokyakarta.

Hendry, ST. 2009.Aplikasi Database dengan Visual Basic 6.0.Jakarta : Kompas Gramedia. 